\title{
EDITORIAL
}

\section{Allostatic load}

\author{
DANTE CICCHETTI \\ University of Minnesota and Mt. Hope Family Center, University of Rochester
}

Homeostasis was the central model guiding stress research for more than a century (Bernard, 1865/1957; Cannon, 1932; Selye, 1956). These homeostatic models depicted the body's internal milieu as being held constant by the self-correcting negative feedback actions of its constituent organ systems (Sterling \& Eyer, 1988). Such physiological systems were conceptualized as working in concert to reestablish the body's initial conditions whenever one or more of the systems exhibited perturbation.

In 1988, Sterling and Eyer, a neurobiologist and an epidemiologist, used the term allostasis to describe the manner in which the body maintains homeostasis through the allocation of metabolic energy to cope with changing environmental demands (Juster, McEwen, \& Lupien, 2009). Major differences between allostasis and homeostasis include the former's emphasis on dynamic as opposed to static biological set points, attention to the role of the brain in the regulation of feedback (Ganzel, Morris, \& Wethington, 2010), and its perspective on health as an adaptation of the entire body to altering contextual requirements (Juster et al., 2009, 2011).

McEwen and Stellar (1993) elaborated upon allostasis, proffering the concept of allostatic load: the price the body pays when confronted with major stressors and sustained stress responses that must be maintained over extended periods of time (Ganzel et al., 2010; McEwen \& Stellar, 1993). Whenever adaptive biological interconnected systems become chronically dysregulated, then maladaptive physiological and psychological sequelae are likely to ensue that may persist across the life span (Juster et al., 2009). Allostatic load models are inherently multilevel and thereby congruent with developmental psychopathology's growing emphasis on the importance of multiple levels of analysis theoretical mod-

Preparation of these Special Issues (Part 1 and Part 2) was supported by grants received from the National Institute of Mental Health (MH54643), the National Institute on Drug Abuse (DA12903, DA17741), and the Spunk Fund, Inc.

Address correspondence and reprint requests to: Dante Cicchetti, Institute of Child Development, University of Minnesota, 51 East River Road, Minneapolis, MN 55455; E-mail: cicchett@umn.edu. els and longitudinal empirical research (Cicchetti \& Toth, 2009). The interdisciplinary perspective advocated by the allostatic load model necessitates the integration of knowledge from multiple scientific fields that must be coordinated with the brain's evaluation of threat and the organization and execution of physiological responses (Ganzel et al., 2010). Just as is the case within the field of developmental psychopathology, research invoking an allostatic load model perspective underscores the criticality of comprehending how the integration of genetic/neurobiological and psychological processes, developmental history, current experiences, and context may eventuate either in adaptive or maladaptive trajectories (Evans \& English, 2002; Juster et al., 2009; Lupien et al., 2006; Lupien, King, Meaney, \& McEwen, 2001; McEwen, 2006).

As elegantly described by Lupien and her colleagues (2006), the processes of allostasis and allostatic load can be conceived as embodying a general biological principle; specifically, that the same systems that help the body adapt to stress and serve a protective function in the short term also may promote pathophysiological processes when overused or managed ineffectively. Furthermore, because the primary mediators of stress access the brain (Cicchetti \& Walker, 2001; Gunnar \& Cheatham, 2003; Ganzel et al., 2010; McEwen, 2006), alterations in thinking and in the processing of affective, cognitive, and social information may result, including the development of psychopathological outcomes (Juster et al., 2011; Lupien et al., 2006; Lupien, McEwen, Gunnar, \& Heim, 2009; Toth et al., in press). Thus, the early detection of allostatic load processes is essential to formulate developmentally timed and guided prevention and intervention strategies.

Because of the exciting research conducted on allostatic load processes in the animal and human literatures, it seemed like an opportune time to devote two Special Issues of Development and Psychopathology to this important topic. The articles in these Special Issues represent contributions from developmentalists from a variety of disciplinary persuasions. Given that some of the same principles that guide research and intervention on allostatic load also undergird the theoretical and empirical work in developmental psychopathology, the potential synergism across these areas has great potential 
to usher in a wave of innovative research that may be translatable into the development of efficacious prevention and in- tervention strategies that could aid in reducing the burden of physical and mental illness across the life span.

\section{References}

Bernard, C. (1957). An introduction to the study of experimental medicine. New York: Dover Publications. (Original work published 1865)

Cannon, W. B. (1932). The wisdom of the body. New York: W. W. Norton.

Cicchetti, D., \& Toth, S. L. (2009). The past achievements and future promises of developmental psychopathology: The coming of age of a discipline. Journal of Child Psychology and Psychiatry, 50, 16-25.

Cicchetti, D., \& Walker, E. F. (2001). Stress and development: Biological and psychological consequences. Development and Psychopathology, $13,413-418$.

Evans, G. W., \& English, K. (2002). The environment of poverty: Multiple stressor exposure, psychophysiological stress, and socioemotional adjustment. Child Development, 73, 1238-1248.

Ganzel, B. L., Morris, P. A., \& Wethington, E. (2010). Allostasis and the human brain: Integrating models of stress from the social and life sciences. Psychological Review, 117, 134-174.

Gunnar, M. R., \& Cheatham, C. L. (2003). Brain and behavior interface: Stress and the developing brain. Infant Mental Health Journal, 24, 195-211.

Juster, R.-P., Bizik, G., Picard, M., Arsenault-Lapierre, G., Sindi, S., Trepanier, L., et al. (2011). A transdisciplinary perspective of chronic stress in relation to psychopathology throughout life span development. Development and Psychopathology, 23, 725-776.

Juster, R. P., McEwen, B. S., \& Lupien, S. J. (2009). Allostatic load biomarkers of chronic stress and impact on health and cognition. Neuroscience and Biobehavioral Reviews, 35, 2-16.
Lupien, S. J., King, S., Meaney, M. J., \& McEwen, B. S. (2001). Can poverty get under your skin? Basal cortisol levels and cognitive function in children from low and high socioeconomic status. Development and Psychopathology, 13, 653-666.

Lupien, S. J., McEwen, B. S., Gunnar, M. R., \& Heim, C. (2009). Effects of stress throughout the lifespan on the brain, behaviour, and cognition. $\mathrm{Na}$ ture Reviews Neuroscience, 10, 434-445.

Lupien, S. J., Ouellet-Morin, I., Hupbach, A., Tu, M. T., Buss, C., Walker, D., et al. (2006). Beyond the stress concept: Allostatic load-A developmental biological and cognitive perspective. In D. Cicchetti \& D. J. Cohen (Eds.), Developmental psychopathology: Vol. 2. Developmental neuroscience (2nd ed., pp. 578-628). New York: Wiley.

McEwen, B. S. (2006). Protective and damaging effects of stress mediators: Central role of the brain. Dialogues in Clinical Neuroscience, 8, 367381.

McEwen, B. S., \& Stellar, E. (1993). Stress and the individual mechanisms leading to disease. Archives of Internal Medicine, 153, 2093-2101.

Selye, H. (1956). The stress of life. New York: McGraw-Hill.

Sterling, P., \& Eyer, J. (1988). Allostasis: A new paradigm to explain arousal pathology. In S. Fisher \& J. Reason (Eds.), Handbook of life stress, cognition and health (pp. 629-649). New York: Wiley.

Toth, S. L., Pickreign Stronach, E., Rogosch, F. A., Caplan, R., \& Cicchetti, D. (in press). Thought disorder in maltreated children. Journal of the American Academy of Child \& Adolescent Psychiatry. 